\title{
The Role of Female Partners in the uptake of Voluntary Medical Male Circumcision in Sub-Saharan Africa: A Review
}

\author{
Celenkosini Thembelenkosini Nxumalo ${ }^{1} \&$ Gugu Gladness Mchunu ${ }^{2}$ \\ ${ }^{1}$ Department of Health, Ndwedwe Community Health Centre, South Africa \\ ${ }^{2}$ School of Nursing and Public Health, UKZN, South Africa \\ Correspondence: Celenkosini Thembelenkosini Nxumalo, BTech Nursing, Master of Nursing) - Professional \\ nurse KZN Department of Health, Ndwedwe Community Health Centre, P100 Canelands Road, South Africa. Tel: \\ 27-32-532-3048; Fax: 27-32-532-3628. E-mail: Thembz92@gmail.com
}

Received: February 23, 2019 Accepted: March 18, 2019 Online Published: May 30, 2019

doi:10.5539/gjhs.v11n7p9 URL: https://doi.org/10.5539/gjhs.v11n7p9

\begin{abstract}
Background: Voluntary Medical Male Circumcision (VMMC) is a proven biological strategy for reducing heterosexual transmission of HIV/AIDS by up to $60 \%$. Following recommendations from the World Health Organisation (WHO), Medical Circumcision (MC) was rolled out in South Africa. Several issues, among them being individual perceptual factors and female partner influence, have constituted as both obstacles and drivers to the uptake of VMMC.
\end{abstract}

Aim: To explore and synthesize research conducted on the role of female partners in the uptake of VMMC.

Methods: Electronic searches were conducted in PUBMED, MEDLINE and CIHNAL, studies included in the review are those that explored the importance of female partner involvement in the uptake of VMMC. The review was limited to sub-Saharan Africa with a focus on peer reviewed articles written in English only.

Results: The review has revealed that considering the gender dimensions of circumcision, the possible utilisation of women as vehicles to drive the uptake of MC could be key to achieving the desired uptake.

Conclusion: It is postulated that women play a key role in terms of promoting circumcision in order to facilitate a successful scale up of the service. Further research is therefore necessary so that the benefits of female partner involvement in VMMC may be achieved.

Keywords: voluntary medical male circumcision, uptake, female partners, sub-Saharan Africa

\section{Introduction}

While over 11 million voluntary medical male circumcisions (VMMC) have been performed in priority sub-Saharan African countries, (Hankins et al., 2016), there are still several barriers that hinder the uptake of VMMC by males (International Initiative for Impact Evaluation, 2013). Historically, circumcision has been widely practised on men and boys for traditional and cultural reasons, particularly in sub-Saharan African and Asia (Goshme, 2012). It is estimated that $30 \%$ of males, the majority of whom are Jewish and Muslim, are currently circumcised worldwide, since these religious groups perform circumcision as part of their religious rituals (WHO \& UNAIDS, 2007).

Recent experimental studies conducted on Medical Male Circumcision (MMC) have provided tangible evidence that MMC reduces the transmission of HIV/AIDS by up to $60 \%$ in female-to-male penetrative sex (Auvert et al., 2005). Moreover, other studies have also proven that other benefits of MMC include; improved penile hygiene, a reduction in the susceptibility to Sexually Transmitted Infections (STIs) such as syphilis, herpes, etc. (Lau, Juykymar, \& Sgaier, 2015). Indirect benefits of MMC for women have also been cited as including the reduced incidence of contracting cervical cancer (Gollaher, 2000).

The increasing number of HIV infections globally, with sub-Saharan Africa being the leading region contributing to this pandemic, warrants additional HIV/AIDS prevention strategies to avert new infections and prevent further complications of the disease. According to the UNAIDS (2010), Southern Africa is home to about two-thirds of the more than 33 million people living with HIV/AIDS in the world. In addition, more than $85 \%$ of the world's AIDS-related deaths have occurred in this region. This HIV epidemic has thus recently contributed to the 
widespread advocacy of Voluntary Medical Male Circumcision (VMMC) as an additional biomedical preventive strategy (Aggleton, 2007). On the African continent, Medical Circumcision (MC) has also been rolled out in response to the rising number of HIV/AIDS related infections and deaths (Gow \& George, 2013). The WHO and UNAIDS $(2011,2016)$ suggest that expanding the coverage of VMMC to $80 \%$ in sexually active men and teenage boys of reproductive age could avoid around 3.5 million people being infected with HIV in the Eastern and Southern African region. This represents a potential cost saving of about 16 billion dollars between 2011 and 2025 (WHO \& UNAIDS, 2011), not to mention the potential for saving lives.

Following recommendations by the WHO and UNAIDS several departments of health in sub-Saharan Africa adopted VMMC as an additional HIV/AIDS prevention strategy following the results of three randomised control trials proving that VMMC is an effective HIV/AIDS prevention strategy, particularly in the prevention of heterosexual transmission of the virus (WHO \& UNAIDS, 2011).

Since the roll-out of VMMC, governments have been robust in their attempt to scale up the services to reach targets set by the WHO so that the benefits of the service can eventually materialise. The review of existing research studies shows that the realisation of the effectiveness of the intervention is dependent on many factors such as addressing individual perceptual factors, namely cultural and religious issues, perceived and actual pain and associated complications, misconceptions about the procedure, perceived lack of female support, etc. (Westercamp \& Bailey, 2007; Sgaier et al., 2015).

Experimental and empirical findings of research conducted have documented extensively the benefits of MMC in terms of HIV reduction in men who are involved in heterosexual relationships. The review of literature has also revealed the indirect benefits of male circumcision for females in terms of the reduction of Sexually Transmitted Infections (STIs) and the decreased risk of contracting cervical cancer. It is for this reason that women are also deemed to play a crucial role in terms of influencing their partners to undergo circumcision (Lanham et al., 2012). It has been found that partner communication plays a key role in the practice of HIV protective behaviours, which include VMMC (Desgrees-Dulou, 2009). The results of a survey conducted by the HIV prevention tracking project revealed that the majority of women would like to partake in decision-making with regards to VMMC (PEPFAIR \& USAID, 2014).

Jones et al. (2014) suggested, in their study aimed at exploring acceptability, knowledge, beliefs and partners as determinants of Zambian men's readiness to undergo MMC, that the discussion of circumcision with a female sexual partner was a predictor of readiness to undergo VMMC. Cook et al. (2016) found that women's acceptance of VMMC significantly impacted on men's decision to undergo MMC, thus the inclusion of female partners in the promotion of VMMC was hypothesised as important.

Taking cognisance of the important role of women regarding the uptake of MMC, it is imperative that women be focused on in terms of communicating accurate information regarding VMMC. Knowledge of the attitudes and perceptions of females regarding MMC is therefore important in order for the appropriate measures to be instituted so that negative stereotypical attitudes and beliefs can be dealt with, allowing the benefits of female involvement to be reaped in terms of the increasing uptake of VMMC.

Madhivanan et al. (2008) found that religion was the strongest correlate for decision-making in terms of MC in Indian mothers. Nevertheless, most mothers with uncircumcised children indicated that they would consider VMMC for their children and recommend it to their spouses if they learned that the procedure would prevent serious health complications. These findings highlighted the need for educational programs to explain the health benefits and risks regarding circumcision so that informed decisions can be taken by these women regarding MC.

In Tanzania, Layer et al. (2013) conducted a qualitative study on women's attitudes and risk perceptions towards MMC. Semi-structured interview guides were used to collect data by means of in-depth interviews conducted on a sample of 33 participants. Although limited in terms of sample size and generalisability, the nature of the data collection process allowed for the results to form an integral foundation in terms of understanding female perceptions of male circumcision. The results of the study showed that MMC was slowly becoming a social norm in Tanzania. In addition, women seemed to demonstrate strong support for MC, which was mainly attributed to the perceived benefits of the procedure to both men and women. However there were misconceptions such as the misperception that it provided direct protection against HIV and protection from all forms of STIs. These perceptions could potentially result in the engagement in risky sexual behaviour on the part of females. It is therefore important that accurate and detailed gender-specific education be provided so that women can make healthy and informed decisions regarding reproductive and sexual health matters.

In a study by Ikwebue, Ross and Ogbonnaya (2015) which explored rural women's knowledge and attitudes 
towards MMC, the authors concluded that women supported MMC, however the low level of knowledge that the participants had regarding the benefits of circumcision was of concern. The authors suggested that such results highlighted the need for an expansion of information to these women.

Scott, Weiss and Viljoen (2005) conducted a study in South Africa to determine the acceptability of MC as an HIV intervention among the Zulu population in KwaZulu-Natal (KZN). Short, structured interviews were carried out on a sample of 144 participants who were male and female. The results showed that most women favoured circumcision for themselves, their partners and male children due to the perceived protective effects of circumcision against STIs.

The results of the study by Maraux et al. (2017) found that women had favoured circumcised men before and after the roll-out of VMMC in South Africa. Furthermore, women had substantially good knowledge about MC. The objective of the study was to assess the knowledge and perceptions of women regarding MC prior to and after its roll-out in South Africa. A community-based, cross-sectional design was employed and data was collected using survey questionnaires from a population of approximately 3000 men and women over a period of three different years.

On the other hand, Mantell et al. (2013) noted that, although women were in support of MC, they also expressed concern about the potential risk of increased HIV infection as a result of men's failure to comply with the sexual abstinence period, moreover, they also expressed concerns that VMMC could potentially result in a refusal by men to engage in protected sexual intercourse. This study was, however, limited in sample size, meaning that the results could not be generalisable to the rest of the KZN population. A further limitation was the choice of the convenience sampling method. The study did, however, make a valuable contribution in terms of the gender dimensions of VMMC.

The role of women in the uptake or scale up of VMMC cannot be over emphasized. According to Semeere et al. (2016), women are considered to be health advocates in the communities they reside in, and are therefore a possible source of demand generation for circumcision, due to their given ability to influence men by providing the correct information and insight about the procedure. Research studies on the acceptability and perceptions regarding VMMC have documented extensively the fact that women occupy a central role in the scale up of VMMC (Westercamp \& Bailey, 2007; Lanham et al., 2012; Maraux et al., 2017). A recent demand creation intervention by Semeere et al. (2016) highlighted the feasibility of pregnant women engaging their partners regarding VMMC. This study, although not statistically significant, contributed to the existing body of knowledge that supports women's role in the uptake of VMMC.

Although much has been documented concerning the fact that women play a crucial role in the scale up of VMMC, there is a dearth of literature on the actual role that women play in generating a demand for VMMC among men. Most research reveals that women are important instruments in the uptake, however sources fail to explicitly illustrate the part that women play, directly or indirectly, in the uptake of VMMC. The literature reviewed merely informs that correct knowledge and perceptions about the procedure are important as this helps direct how and what information female partners give their male counterparts to encourage them to undergo VMMC. According to Lanham et al. (2012), women are an important audience for VMMC scale up interventions. It therefore becomes imperative to explore the actual role they play in the uptake of VMMC, hence the review of studies that explore this role becomes necessary to determine the extent of such literature, its strengths and weaknesses, so that recommendations for policy and future research can be made.

\section{Methods}

\subsection{Data Sources and Search Strategies}

The criteria for studies to be considered in this review were established before the review of the literature and included studies that explored the role of women in the uptake of VMMC or highlighted the importance of female partner involvement in interventions directed towards the scale up of VMMC (Table 1). The review sought to include only formal studies or papers emanating from the sub-Saharan African region, published in peer-reviewed journals or presented at international conferences. The electronic searches were conducted in CINAHL, MEDLINE and PUBMED. The search words used were: "Voluntary Medical Male Circumcision" AND "The role of women" and "Women" AND "Voluntary Medical Male Circumcision". The results of the above searches only generated nine articles, only three of which dealt explicitly with the actual role played by women in the uptake of VMMC (Table 2). Other articles which are included in the introduction pertained to the knowledge, perception and acceptability of females regarding voluntary medical male circumcision. These studies are included in the review as they strengthen the knowledge base concerning the fact that women have an important role to play in the uptake 
of VMMC. However, for the purpose of this review, the two studies that were found which address the actual role of women are scrutinised in terms of literature and application of research methodology. The other studies serve to strengthen the background of this review and further highlight the gap in the literature in terms of research exploring the role of females in influencing male partners to undergo VMMC. The summary of article selection for this review can be seen in Figure 1.

\subsection{Summary of Inclusion and Exclusion Criteria}

Table 1. Inclusion and exclusion criteria

\begin{tabular}{ll}
\hline Inclusion criteria & Exclusion criteria \\
\hline Articles written in English only & Articles not written in English \\
\hline $\begin{array}{l}\text { Studies exploring women or female partner's roles in the } \\
\text { uptake of VMMC }\end{array}$ & $\begin{array}{l}\text { Studies exploring groups either than women or female } \\
\text { partners in the uptake of VMMC }\end{array}$ \\
\hline Study setting limited to sub-Saharan Africa & Study setting outside sub-Saharan Africa \\
\hline
\end{tabular}

\begin{tabular}{|c|c|}
\hline \multicolumn{2}{|c|}{ Identification } \\
\hline $\begin{array}{l}2018 \text { records found through databases } \\
\text { searched }\end{array}$ & $\begin{array}{l}1718 \text { records removed after setting of } \\
\text { limiters and } 221 \text { duplicates removed }\end{array}$ \\
\hline \multicolumn{2}{|c|}{ Screening } \\
\hline $\begin{array}{l}75 \text { records entered into title and abstract } \\
\text { review }\end{array}$ & $\begin{array}{l}66 \text { articles excluded for not meeting } \\
\text { inclusion criteria }\end{array}$ \\
\hline \multicolumn{2}{|c|}{ Eligibility and inclusion } \\
\hline $\begin{array}{l}9 \text { full text articles included for eligibility } \\
\text { female partners in the uptake of VMMC. }\end{array}$ & 3 explicitly dealing with the actual role of \\
\hline
\end{tabular}

Figure 1. Article selection process

\section{Results of Search Strategy}

The results of the review revealed only 9 citations on the three search engines utilised. The results of most of the studies found show that women have a crucial role to play in the uptake of VMMC, in most studies acceptance and correct perception about the procedure was seen to be a predictor for successful uptake of VMMC.

The research studies included are diverse in terms of the methodologies they used in order to meet the objectives of 
the study. The common strength in the qualitative studies found was the fact that in-depth interview and discussion was conducted with the target population, however there were weaknesses in the diversity of the study samples in terms of demographic characteristics and geographical location and therefore generalisability is to be questioned.

The strengths in the quantitative studies were in that they had a reasonable sample size and efforts to ensure validity and reliability were instituted such as pilot studies etc. However most of these studies were limited to South Africa and Kenya. More of such type of studies are required though the rest of Sub-Saharan Africa.

In most studies in the review the role of women in the uptake of VMMC was explore as part of a meeting a broader aim of the studies as opposed to it being the main aim of the study. The results of the review and papers found are summarized in Table 2 .

Table 2. Summary of research papers found

\begin{tabular}{|c|c|c|c|c|}
\hline Title & Research objective(s) & $\begin{array}{l}\text { Country } \\
\text { and year }\end{array}$ & Research methods & Key findings \\
\hline $\begin{array}{l}\text { Women's roles in } \\
\text { voluntary medical } \\
\text { male circumcision. }\end{array}$ & $\begin{array}{l}\text { To assess: } \\
\text { - Women's understanding of } \\
\text { VMMC's partial protection } \\
\text { against HIV. } \\
\text {-Couples' communication } \\
\text { about VMMC. } \\
\text {-Women's engagement } \\
\text { before and after the } \\
\text { procedure. }\end{array}$ & $\begin{array}{l}\text { Kenya } \\
(2012)\end{array}$ & $\begin{array}{l}\text { Two phase } \\
\text { In-depth interviews, } \\
\text { individual and focus group. }\end{array}$ & $\begin{array}{l}\text { Women play an important role in } \\
\text { encouraging men to get circumcised, } \\
\text { hence reaching out to them is } \\
\text { valuable, especially from a VMMC } \\
\text { communication point of view. }\end{array}$ \\
\hline
\end{tabular}

Innovative demand creation for VMMMC targeting high impact male population: A pilot study engaging pregnant women at antenatal clinics.
To evaluate an approach at increasing uptake of circumcision within the context of an integrated antenatal care setting.
Uganda

(2016)

Pilot behaviour change intervention using a

Quasi-experimental design.

The intervention had no significant impact on increasing the demand for VMMC in this cohort, but highlighted the feasibility and importance of engaging women in the uptake of VMMC.

Women's knowledge and perception of male circumcision before and after its roll-out.
To assess knowledge and perceptions of women regarding male circumcision in a setting before and after its roll-out.

$\begin{array}{lll}\text { South } & \text { Community- } & \text { based, } \\ \text { Africa } & \text { cross-sectional } & \text { survey } \\ (2016) & \text { spanning three years. }\end{array}$

To examine the role of

Factors associated with married women's support of male circumcision for HIV prevention. women's sociodemographic characteristics, knowledge of HIV and sexual bargaining power as determinants of women's support for male circumcision.
Uganda A population- based, cross-

(2016) sectional survey.
Findings show that women demonstrate a favourable perception towards and knowledge of the procedure. The study highlighted that women should participate in VMMC promotion campaigns.

A positive correlation exists between women's education level and knowledge of the benefits of VMMC which may correlate with support for VMMC and thus influence uptake among males. Women's ability to negotiate safe sex practices may influence uptake of VMMC.

Women supported MMC, however

Rural Zulu women's knowledge and attitudes of and towards medical male circumcision.
To explore Zulu women's South knowledge and attitudes Africa towards MMC.
Quantitative survey design of 590 pregnant, isiZulu-speaking women. accurate knowledge base was poor, and prompting the need for education campaigns for these women, as the amount of female knowledge is hypothesised to influence uptake and acceptability of VMMC. 


\begin{tabular}{|c|c|c|}
\hline $\begin{array}{l}\text { circumcision and HIV perspectives of MMC. } \\
\text { risk: Perceptions of } \\
\text { women in higher } \\
\text { institutions of learning }\end{array}$ & $\begin{array}{l}\text { Africa } \\
(2013)\end{array}$ & $\begin{array}{l}\text { female perceptions regarding } \\
\text { VMMC possibly stemming from } \\
\text { long term gender inequalities. This } \\
\text { study highlighted the need for these } \\
\text { inequalities to be addressed so that } \\
\text { women facing these challenges can } \\
\text { overcome them to the point where } \\
\text { they can exercise their individual } \\
\text { roles in the scale up of VMMC. }\end{array}$ \\
\hline
\end{tabular}

\begin{tabular}{|c|c|c|c|c|}
\hline $\begin{array}{l}\text { "If you are not } \\
\text { circumcised, I cannot } \\
\text { say Yes" - The role of } \\
\text { women in promoting } \\
\text { the uptake of VMMC } \\
\text { in Tanzania. }\end{array}$ & $\begin{array}{l}\text { To analyse women's } \\
\text { influence on the uptake of } \\
\text { VMMC as reported by men } \\
\text { and women. }\end{array}$ & $\begin{array}{l}\text { Tanzania } \\
\text { (2015) }\end{array}$ & $\begin{array}{l}\text { Qualitative, in-depth } \\
\text { interview and participatory } \\
\text { group discussions with men } \\
\text { and women. }\end{array}$ & $\begin{array}{l}\text { Participants revealed that women } \\
\text { have a role in the uptake of VMMC, } \\
\text { directly and indirectly, by provision } \\
\text { of accurate advice about VMMC and } \\
\text { denying sex to partners not } \\
\text { circumcised. The study findings } \\
\text { suggest that expanding } \\
\text { communication strategies to include } \\
\text { women could significantly increase } \\
\text { uptake of the service. }\end{array}$ \\
\hline $\begin{array}{l}\text { Female partner } \\
\text { acceptance as a } \\
\text { predictor of men's } \\
\text { readiness to undergo } \\
\text { VMMC in Zambia: } \\
\text { The spear and shield } \\
\text { project. }\end{array}$ & $\begin{array}{l}\text { To examine the relationship } \\
\text { between changes in women's } \\
\text { acceptance of VMMC and } \\
\text { men's readiness to undergo } \\
\text { the procedure. }\end{array}$ & $\begin{array}{l}\text { Zambia } \\
(2016)\end{array}$ & $\begin{array}{l}\text { A parallel intervention } \\
\text { model guided by a } \\
\text { mediation model to } \\
\text { examine the relationship } \\
\text { between the changes in } \\
\text { women's acceptance. }\end{array}$ & $\begin{array}{l}\text { Women's acceptance of VMMC } \\
\text { significantly impacted on men's } \\
\text { decision to undergo VMMC, thus } \\
\text { supporting previous studies which } \\
\text { emphasise the importance of } \\
\text { including female partners in VMMC } \\
\text { promotion efforts. }\end{array}$ \\
\hline
\end{tabular}

\section{Discussion}

Through the literature search conducted on electronic databases, only nine recent studies were found which investigated the role of women in the uptake of VMMC in sub-Saharan Africa. The few studies found were diverse in their research approaches to answering their objectives. Across the studies it was found that the level of acceptance regarding VMMC was great. Furthermore, the degree of knowledge, coupled with females' acceptance of the procedure, positively correlated with an increase in the uptake of VMMC. Although it is not clear exactly what it is about acceptability and knowledge that influences the uptake of VMMC, the literature does state that it increases uptake in the sense that women are able to act as motivators for circumcision, based on their level of knowledge and hence acceptability of the process becomes key. In addition to knowledge and acceptance, females' perceptions, behaviours and reactions towards safe sex practices play a role, in the sense that VMMC promotes hygiene, safe sex practices such as condom use and, subsequently, a reduction of sexually transmitted infection on the part of both males and females. Therefore, females' ability to negotiate safe sex either through education or denying of sex to males in the event that this does not occur, also influences the uptake of VMMC. This highlights the direct role that women play in the uptake of VMMC.

Baily et al. (2012) postulate that women's beliefs about circumcision influence men's acceptance of the procedure due to women's strong emphasis on penile hygiene and a desire to be protected from sexually transmitted infections. On the other hand, gender norms may contribute to a failure by women to be able to negotiate safe sex practices including VMMC, hence it becomes necessary for gender inequalities be dealt with at community level so that the benefits of female partner involvement in VMMC may be fully realised. Research in this area would be instrumental. Concurring with this, Perez et al. (2014) state that research studies carried out on VMMC using a gendered approach could provide a significant foundation for the development of policy and evidence-based implementation strategies to support and enhance the uptake of VMMC.

Cultural and religious notions associated with MC circumcision and the involvement of women must also be addressed, especially since these play a huge role in the way in which individuals respond to a particular disease and even specific health actions (Andrews \& Boyle, 1999). Religion and culture are often used interchangeably by scholars to depict a sense of shared values which have an influence on human behaviours and may ultimately affect or influence the human response to health interventions. Hyder and Marrow (2005) argue that programs which fail 
to engage the indigenous practices and beliefs of individuals cease to reach their goals. It thus becomes necessary that, with the involvement of women in medical circumcision, the religious and cultural beliefs governing women; sexuality; sexual roles and dynamics also be taken into account to ensure the yield of the maximum results from the benefits of female partner involvement in the uptake of VMMC.

More research is, however, required to explore the role of women in the uptake of VMMC. It is suggested that further qualitative studies be conducted to deduce from circumcised males the roles of their partners in their decision to undergo circumcision. Moreover studies on female partners of circumcised men should be conducted, in order to understand the roles they have played in encouraging their partners to undergo VMMC.

\subsection{Limitations}

The results of this review are limited in that only electronic search of papers were conducted and included only those research articles which were written in English which might have resulted in the exclusion of some pertinent studies. Furthermore only studies which met that inclusion criteria of the review, that is having addressed the role of women in either as an objective or as part of the discussion was included and this might have limited the scope of the review. Since the review of the study was limited in that only few articles were found and all were included, there was no real synthesis and critique of the findings and research methods as the methodologies were diverse.

\subsection{Recommendations}

It is suggested that further research be done to explore, analyse and understand the exact role that women play in the uptake of VMMC. Phenomenological and phenomenogrpahic studies need to be conducted to explore the experiences of women whose partners have undergone medical circumcision. In addition research also needs to be done to explore how women construct and perceive circumcision in varying context so that a more holistic understanding of VMMC may be attained

Participatory and action research needs to be conducted in order to deal with the gender norms of femininity and masculinity so that the benefits of female partner involvement in $\mathrm{MC}$ can be achieved. Policy makers must take into account and deal with gender norms associated with $\mathrm{MC}$ if we are to realise the benefits of female partner involvement in VMMC.

\section{Conclusion}

The review of research proves that women have a direct and indirect role to play in the uptake of VMMC by males, particularly their partners and adolescent male children. Acceptance and accurate knowledge about the nature and benefits of the procedure is crucial if women are to be used in campaigns to advocate for VMMC. Research shows that there is a positive correlation between partner acceptance and awareness of medical circumcision and uptake of VMMC by males. In order for the benefits of circumcision to materialise, part of the intervention strategy must involve females, hence it becomes necessary for more research to be conducted to determine the exact role of women in the uptake of VMMC. Existing female partners of circumcised men would be instrumental in this area of research.

\section{Aknowledgements}

The research reported in this publication was supported by the Fogarty International Center (FIC), NIH Common Fund, Office of Strategic Coordination, Office of the Director (OD/OSC/CF/NIH), Office of AIDS Research, Office of the Director (OAR/NIH), National Institute of Mental Health (NIMH/NIH) of the National Institutes of Health under Award Number D43TW010131. The content is solely the responsibility of the authors and does not necessarily represent the official views of the National Institutes of Health.

\section{Competing Interests Statement}

The authors declare that there are no competing or potential conflicts of interest.

\section{References}

Andrews, M. M., \& Boyle, J. S. (1999). Transcultural concepts in nursing care. Philadelphia: J.B. Lippincott. https://doi.org/10.1177/104365969901000302

Aggleton, P. (2007). Roundtable: "Just a snip"?: A social history of male circumcision. Reproductive Health Matters, 15(29), 15-21. https://doi.org/10.1016/S0968-8080(07)29303-6

Auvert, B., Taljaard, D, Legarde, E., Sobngwi-Tambekou, J., Sitta, R., \& Puren, A. (2005). Randomized controlled intervention trial of male circumcision for reduction of HIV infection risk: the ANRS 1265 trial. PLoS Med, 2(11), 298. https://doi.org/10.1371/journal.pmed.0020298 
Bailey, R. C., Muga, R., Poulussen, R., \& Abicht, H. (2002). The acceptability of male circumcision to reduce HIV infections in Nyanza Province, Kenya. AIDS Care, 14(1), 27-40. https://doi.org/10.1080/09540120220097919

Doyle, D. (2005). Ritual male circumcision: A brief history. Journal of Royal College of Physicians Edinburgh, 25, 279-285.

Gollaher, D. (2000). Circumcision: A history of the world's most controversial surgery. New York: Basic Books.

Goshme, Y. M. (2012). Factors influencing the uptake of male circumcision as HIV Prevention Strategy among adolescent boys in Nanogang Community Junior Secondary School (NCJSS). Gaborone, Botswana.

Hankins, C., Warren, M., \& Njeuhmeli, E. (2016). Correction: Voluntary Medical Male Circumcision for HIV Prevention: New Mathematical Models for Strategic Demand Creation Prioritizing Subpopulations by Age and Geography. PLOS ONE, 11(12), e0169499. https://doi.org/10.1371/journal.pone.0169499

Hyder, A. A., \& Morrow, R. H. (2005). Culture, behaviours and health.

Ikwebue, J. N., Ross, A., \& Ogbonnaya, H. (2015). Rural Zulu women's knowledge and attitudes towards medical male circumcision. Africa Journal of Primary Health Care and Family Medicine, 7(1), 1-6.

Jones, D., Cook, R., Arheart, K., Redding, C. A., Zulu, R., Castro, J., \& Weiss, S. M. (2014). Acceptability, Knowledge, Beliefs, and Partners as Determinants of Zambian Men's Readiness to Undergo Medical Male Circumcision. AIDS and Behaviour, 18(2), 278-284. https://doi.org/10.1007/s10461-013-0530-0

Lau, F. K., Jayakumar, S., \& Sgaier, S. (2015). Understanding the socio-economic and sexual behavioral correlates of male circumcision across eleven voluntary medical male circumcision priority countries in southeastern Africa. BMC Public Health, 15(813), 1-11.

Lanham, M., L'Engle, K. L., Loopapit, M., \& Oguma, I. O. (2012). Women's Roles in voluntary medical male circumcision in Nyanza province, Kenya. PLoS ONE, $7(9), \quad 1-5$. https://doi.org/10.1371/journal.pone.0044825

Layer, E. H., Beckham, S. W., Mgeni, L., Shembilu, C., Momburi, R. B., \& Kennedy, C. E. (2013). After my husband's circumcision, I know that I'm safe from diseases: Women's attitudes and risk perceptions towards male circumcision in Iringa, Tanzania. PLoS ONE, 8(8), 1-8. https://doi.org/10.1371/journal.pone.0074391

Madhivanan, P., Krupp, K., Chandrasekaran, V., Karat, S. C., Reingold, A. L., \& Klausner, J. D. (2008). Acceptability of male circumcision among mothers with male children Mysore, India. AIDS, 22(8), 983-988. https://doi.org/10.1097/QAD.0b013e3282ffde52

Mandova, E., Mutonhri, \& Mudzanire, S. (2013). The cultural significance and relevance of the shangeni rite of male circumcision in the light of HIV and AIDS mitigation in Zimbabwe. International Journal of Asian Social Science, 15(3), 1-8.

Mantell, J. E., Smit, J. A., Saffitz, J. L., Milford, C., Mosery, N., Mabude., Z., ... Stein, Z. A. (2013). Sex Health, 10(2), 112-118. https://doi.org/10.1071/SH12067

Maraux, B., Lissouba, P., Rain-Taljaard, R., Taljaard, D., Bouscaillou, J., Lewis, D., Puren, A., \& Auvert, B. (2017). Womens knowledge and perception of male circumcision before and after its roll-out in the South African township of Orange Farm from community-based cross-sectional surveys. PLoS ONE, 12(3), 1-10. https://doi.org/10.1371/journal.pone.0173595

Perez, G. M., Duran, L. T., Gasch, A., \& Desmond, N. (2015). Towards a gender perspective in qualitative research on voluntary medical male circumcision in East and Southern Africa. Global Public Health, 10(5-6), 626-638. https://doi.org/10.1080/17441692.2015.1014826

PEPFAR \& USAID. (2014). Integrating Gender in voluntary medical male circumcision programs to improve outcomes. USAID Assist project.

Scott, B. E., Weiss, H. A., \& Viljoen, J. I. (2005). The acceptability of male circumcision as an HIV intervention among a rural Zulu population, KwaZulu-Natal, South Africa. AIDS Care, 17(3), 304-313. https://doi.org/10.1080/09540120412331299744

Semeere, A. S., Castelnuovo, B., Bbaale, D. S., Kiragga, A. N., Kigozi, J., Muganzi, A. M., \& Kambugu, A. (2016). Innovative Demand Creation for Voluntary Medical Male Circumcision Targeting a High Impact Male Population: A Pilot Study Engaging Pregnant Women at Antenatal Clinics in Kampala, Uganda. Journal of Acquired Immune Deficiency Syndromes (1999), 72(4), 278-284. 
Sgaier, S. K., Reed, J. B., Thomas, A., \& Njeuhmeli, E. (2014). Achieving the HIV prevention impact of voluntary medical male circumcision: Lessons and challenges for managing programs. PLoS Medicine, 11(5), 1-9. https://doi.org/10.1371/journal.pmed.1001641

UNAIDS. (2010). Global report: UNAIDS report on the global AIDS epidemic 2010.

Westercamp, N., \& Bailey, R. C. (2007) Acceptability of male circumcision for prevention of HIV/AIDS in Sub-Saharan Africa: a review. AIDS Behavior, 11, 341-355. https://doi.org/10.1007/s10461-006-9169-4

WHO \& UNAIDS. (2007). New data on male circumcision and HIV prevention: Policy and program implications. Geneva, Switzerland: WHO Press.

WHO \& UNAIDS. (2011). Joint strategic framework to accelerate the scale-up of voluntary medical male circumcision for HIV prevention in Eastern and Southern Africa. Geneva, Switzerland: WHO Press.

\section{Copyrights}

Copyright for this article is retained by the author(s), with first publication rights granted to the journal.

This is an open-access article distributed under the terms and conditions of the Creative Commons Attribution license (http://creativecommons.org/licenses/by/4.0/). 